\title{
A prova social da escolarização entre jovens de escolas públicas: trabalho e interatividade sociável nas periferias de Porto Alegre
}

Leandro Rogério Pinheiro

RESUMO

Nossas problematizações partem de resultados de pesquisa em localidades de periferia, destacando informações produzidas entre 2017 e 2019, em três bairros de Porto Alegre/RS. Buscamos compreender como os jovens confrontam a prova social da escolarização em estabelecimentos públicos sediados em tais contextos. Contribuições de Danilo Martuccelli são as referências teórico-metodológicas centrais, sendo que, em campo, dedicamo-nos à aplicação de questionários e à realização de grupos de discussão e entrevistas narrativas. As interlocuções assinalaram uma implicação mútua entre práticas sociáveis e institucionais, de forma que modos de presença interativa percorriam diferentes níveis de ensino. A escolarização era experienciada em associação ao imperativo do trabalho e, também, sob o desafio da produção de sentidos ao presente na instituição. Nesse cenário, aventamos que a prova social da escolarização concorre às individuações mobilizando táticas metonímicas e interações singularizantes.

PALAVRAS-CHAVE

escolarização; juventudes; sociabilidades; trabalho; periferias.

'Universidade Federal do Rio Grande do Sul, Porto Alegre, RS, Brasil. 


\title{
SOCIAL PROOF OF SCHOOLING AMONG YOUNG PEOPLE FROM PUBLIC SCHOOLS: WORK AND SOCIABLE INTERACTIVITY IN THE OUTSKIRTS OF PORTO ALEGRE
}

\begin{abstract}
This research was conducted in three peripheral neighborhoods of Porto Alegre/RS between 2017 and 2019. We seek to understand how youths confront the social proof of schooling in public facilities. Contributions by Danilo Martuccelli are our main references; data were collected via questionnaires, discussion groups, and narrative interviews. The interlocutions evinced a relationship between sociable and institutional practices and interactive modes of presence, which were showed through different levels of education. Schooling was experienced in articulation with the working imperative and under the challenge of producing meaning to their current situation in the institution. Therefore, we argue that the social proof of schooling fosters individuation by mobilizing metonymic tactics and singularizing interactions.
\end{abstract}

KEYWORDS

schooling; youngsters; sociability; work; peripheries.

\section{LA PRUEBA SOCIAL DE LA ESCOLARIZACIÓN ENTRE JÓVENES DE ESCUELAS PÚBLICAS: TRABAJO E INTERACTIVIDAD SOCIABLE EN LAS PERIFERIAS DE PORTO ALEGRE}

\section{RESUMEN}

Las problematizaciones del presente artículo parten de resultados de investigación producida entre 2017 y 2019 en la periferia urbana de la ciudad de Porto Alegre, estado de Rio Grande do Sul. Tratamos de comprender cómo los jóvenes se enfrentan a la prueba social de la escolarización en establecimientos públicos de estos contextos. Las contribuciones de $\mathrm{Da}-$ nilo Martuccelli son los referentes teórico-metodológicos centrales. En campo, se realizó la aplicación de cuestionarios y la realización de grupos de discusión y entrevistas narrativas. Las interlocuciones señalaron una implicación mutua entre prácticas sociables e institucionales, de manera que los modos de presencia interactiva atravesaban los diferentes niveles de enseñanza. La escolarización se experimentaba en asociación con el imperativo del trabajo y bajo el reto de producir sentidos referidos al presente en la institución. Así, planteamos que la prueba social de la escolarización concurre a las individuaciones, movilizando tácticas metonímicas e interacciones singularistas.

PALABRAS-CLAVE

escolarización; juventudes; sociabilidad; trabajo; periferias. 


\section{INTRODUÇÃO}

Para quem transita regularmente por localidades socialmente vulnerabilizadas das cidades e dialoga com seus moradores, não é incomum conhecer narrativas sobre percursos biográficos construídos a medida das necessidades e/ou da interposição de precariedades materiais e culturais. Os depoimentos sobre as dificuldades para permanência e sucesso na escola estão entre eles, não raro, assinalando certo arrependimento pelo esforço supostamente não empreendido ou, por vezes, silenciando apenas, em constrangimento.

Nas últimas décadas, no entanto, percebemos relativa inflexão rumo à ampliação dos anos de estudo, à conclusão da educação básica e ao adiamento da inserção no mundo do trabalho (Sposito, Souza e Silva, 2018). Fato pertinente, que coloca questões sobre a permanência estendida na escola, especialmente entre jovens-adolescentes, e suas possíveis repercussões no cotidiano de famílias de classes populares. Entretanto, sabe-se também das elevadas taxas de evasão escolar ainda presentes, particularmente no ensino médio, e a existência de trajetórias escolares truncadas, em meio à precarização de condições de vida e medidas de correção de fluxo voltadas à permanência do aluno, ainda que sob risco de desalento e estigmatização (Julião e Ferreira, 2016). Cenário que, ademais, constitui-se em instabilidade agravada pelo atual quadro de retração dos investimentos governamentais em áreas sociais ${ }^{1}$.

Tal contexto de conquistas instáveis, com a permanência na escola de segmentos antes excluídos, é perpassado ainda pela diversificação das referências simbólicas e de acesso à informação (Dubet e Martuccelli, 1998). De uma parte, a navegação por tecnologias de informação e comunicação (TIC) é crescente, com destaque entre os segmentos juvenis (Kubota, 2016). De outra, desde o início dos anos 2000, pesquisas indicam a importância atribuída à sociabilidade entre pares nas diferentes práticas culturais produzidas por jovens (Dayrell e Carrano, 2014), tendendo a perpassar as rotinas escolares inclusive. Panorama esse que tem instigado pesquisadores no campo da sociologia das juventudes a considerarem os itinerários e as experiências produzidas pelos indivíduos, como partícipes de seus processos de socialização e individuação.

Nessa perspectiva, e frente a tal cenário, o artigo ocupa-se de problematizar como os jovens confrontam a prova social da escolarização em estabelecimentos públicos sediados em localidades de periferia de Porto Alegre, Rio Grande do Sul. Tomamos a noção de "prova" tal como proposta por Martuccelli $(2007,2018)$, articulando-a a processos de individuação. Em campo, organizamos as incursões desde a aplicação de questionários, à realização de grupos de discussão e à efetivação de entrevistas. Assim, obtivemos uma leitura geral de práticas e preferências dos sujeitos na escola, passando, depois, às suas elaborações a respeito e à associação com suas narrativas biográficas.

1 Uma análise sucinta e pertinente do quadro atual do acesso de jovens à escola pode ser encontrada em Zan e Krawczyk (2020). 
Os dados trazidos, aqui, sistematizam algumas de nossas inferências, ao dispô-las para discussão desde a indicação do que denominamos "formas de presença" na escola, com vistas a discutir o comum e o diverso nas experiências de escolarização das quais nos aproximamos. É este um modo de ponderarmos, ademais, os agenciamentos táticos operados pelos jovens estudantes e dispor em tela a análise, ainda que liminar, de uma prova social específica e sua inter-relação com individuações em processo.

Dessa forma, apresentaremos nossos referentes de pesquisa e uma caracterização resumida das informações coletadas a seguir. Então, passaremos ao exame dos dados e exposição do que, neste momento da pesquisa, aventamos ser significativo para compreensão do que afeta e mobiliza os jovens em seu tempo na escola, quando vamos a localidades de periferia.

\section{CONTEXTO E REFERENTES}

Como já mencionado, trabalhamos para compreender as vivências da escolarização em localidades de periferia urbana, tomando as contribuições de Martuccelli (2007, 2010, 2018) e, mais especificamente, a noção de "prova social". Cabe, então, expor com um pouco mais de detalhe nossa apropriação do referencial teórico-metodológico. Tal categoria é apresentada como artifício heurístico, articulando experiências pessoais e processos sociais para cenários em que as dinâmicas de individuação a partir de marcadores macroestruturais necessitam de problematização, dado o que o autor caracteriza como uma crescente singularização dos percursos de vida na contemporaneidade.

Nesse sentido, Martuccelli (2018) considera necessário conduzirmos a pesquisa também ao "trabalho dos indivíduos", e não só às prescrições socioinstitucionais, como fizeram as teorias da individualização. $\mathrm{O}$ autor busca as experiências construídas nas interações sociais, de modo que possa ampliar a compreensão dos movimentos que os sujeitos fazem, sem perder de vista categorias macro analíticas usuais.

Martuccelli (2007) atribui quatro características principais às "provas-sociais”. Primeiramente, elas apresentam uma dimensão narrativa desde a qual os sujeitos entendem seus percursos e dispõem desafios constituintes, como herdeiros de uma aventura propriamente moderna. Segundo, trazem referências às capacidades dos indivíduos para fazer frente às provas, em geral, aventadas como tarefas pessoais. Remetem-nos também a processos de avaliação social, a partir dos quais cabe observar os diferenciais de resposta e os recursos efetivamente mobilizados para tanto. E, por fim, articulam-se a um conjunto de desafios estruturais compulsórios e significativos no marco de determinada sociedade, sejam eles institucionalizados ou relativos à produção de laços sociais, e variáveis conforme período histórico.

Isso posto, uma questão complementar se orienta às bases que sustentam a existência dos indivíduos, para chegarmos ao que o autor denomina "suportes". Martuccelli (2007) busca delimitar o conjunto de recursos e apoios que constituem as experiências dos atores, como uma ecologia existencial dos elementos apropriados 
no processo de individuação. Enfatiza o autor que não se trata de um inventário das condições e capitais disponíveis conforme a posição social, mas, do reconhecimento do que se inscreve na trama de interdependências efetivas das histórias individuais, apoiando os indivíduos a terem-se como tais.

A apropriação dessas noções presta-se a uma mirada aos indivíduos como ponto de inteligibilidade sociológica: certo olhar indutivo que complemente e/ou desborde marcadores estruturais. Aqui, é questão a identificação de "estados sociais" que caracterizem contextos e modos de produção dos processos de individuação pelos atores, transversalizando posições sociais já conhecidas; e, ao mesmo tempo, a nuance desses "estados" conforme lógicas posicionais e temporais (Martuccelli, 2018). Tal exercício compôs, por exemplo, as inferências de Araújo e Martuccelli (2011) acerca da "inconsistência posicional" experienciada pelos cidadãos chilenos, como mobilizador de extensas jornadas de trabalho e um significativo componente da individuação naquela sociedade.

\section{EM CAMPO}

As localidades nas quais desenvolvemos a pesquisa abordada são os bairros Cruzeiro, Lomba do Pinheiro e Restinga. Todos têm histórico de crescimento populacional expressivo nos anos 1960-70, por conta de fluxos migratórios do interior do estado ou de deslocamentos entre áreas da cidade, fenômenos esses associados, no país, a medidas governamentais que provocaram intenso êxodo rural para regiões metropolitanas e à dinâmica do mercado imobiliário, que tende a empurrar contingentes empobrecidos para as margens da urbe (Moura, 1996). Considerando séries estatísticas publicadas pelo Observatório da Cidade de Porto Alegre (ObservaPoa, 2017), uma análise comparativa evidencia que aquelas localidades estavam entre as mais vulnerabilizadas econômica e culturalmente.

A pesquisa que conduzimos assume a escolarização como prova estrutural. Seja por sua recorrente associação à mobilidade social via articulação ao mundo do trabalho, conforme indica a literatura ${ }^{2}$; seja por conta de nossas incursões etnográficas e entrevistas em contextos de periferia urbana na cidade, realizadas desde 2011, e partir das quais observamos regulares esforços individuais e/ou familiares de investimento na carreira escolar, sob a expectativa de melhoria de condição de vida. Em que pesem as tensões para permanência na escola em contextos vulnerabilizados, a relação com a instituição tem se mostrado mobilizadora e referencial na narração dos logros e fracassos dos indivíduos.

2 É de conhecimento que as posições sociais no Brasil, entre outros países capitalistas, são reguladas também pelo status educacional comparativo historicamente produzido. Dados do Instituto Brasileiro de Geografia e Estatística (IBGE) vem sinalizando para a relação entre escolaridade e nível de remuneração. As análises de Jessé Souza (2009) têm assumido, ademais, o capital cultural como um dos marcadores de mobilidade e desigualdade social para a realidade brasileira. Sobre as expectativas de grupos populares em relação aos percursos escolares e sua associação ao trabalho, ver, por exemplo, Zago (2012). 
Delineamos o trabalho em campo mediante interlocução com jovens alunos de diferentes níveis de ensino, em escolas públicas sediadas nos bairros supracita$\operatorname{dos}^{3}$. Primeiramente, a investigação ancorou-se na aplicação de questionários sobre consumos culturais e habitação da escola. Até a conclusão desta escrita, tínhamos chegado a 583 observações (146 para Cruzeiro; 180 para Lomba do Pinheiro; e 257 para Restinga). A amostragem foi intencional e não probabilística, sendo o acesso aos alunos realizado conforme conseguíamos a anuência das instituições educativas, atentando, entretanto, para que tivéssemos escolas públicas municipais, estaduais e federais (quando existiam nas localidades) e presença expressiva de jovens alunos. Esse tipo de amostra não permite extrapolações estatísticas, mas se presta a análises significativas particularmente se usadas com apoio de outras técnicas (Field, 2009) ${ }^{4}$. Nesse sentido, o instrumento utilizado foi um questionário estruturado, autoaplicável e com questões fechadas sobretudo, empregando entre abril de 2017 e junho de 2019.

Com os questionários, a população consultada se distribuía entre jovens-adolescentes (52\%), jovens entre 18 e 24 anos (29\%), jovens entre 25 e 29 anos (13\%) e adultos (6\%). Pessoas do sexo feminino representavam $58 \%$ das observações e, para a autodeclaração de cor, tivemos $47,6 \%$ brancos e $52,4 \%$ negros (pretos e pardos). Dentre os que indicaram renda familiar (393 observações), 62,5\% indicaram renda familiar de até dois salários mínimos $(\mathrm{SM}), 28 \%$ registraram entre dois e cinco SM e 9,5\% mais de cinco SM. Vale frisar, constatou-se correlação significativa entre escolaridade e renda na amostra.

Em relação aos estabelecimentos e níveis de ensino, a Tabela 1 expressa a distribuição.

Tabela 1 - Distribuição de observações por local de aplicação.

\begin{tabular}{|c|c|c|c|c|c|c|}
\hline \multirow[b]{2}{*}{$\begin{array}{l}\text { Nível de } \\
\text { ensino }\end{array}$} & \multicolumn{5}{|c|}{ Locais de aplicação } & \multirow[b]{2}{*}{ Total } \\
\hline & $\begin{array}{c}\text { Esc. Munic. } \\
\text { - EJA } \\
\text { (Ts finais) }\end{array}$ & $\begin{array}{c}\text { Esc. Est. } \\
\text { - EM }\end{array}$ & $\begin{array}{c}\text { Inst. } \\
\text { Fed. - } \\
\text { PROEJA }\end{array}$ & $\begin{array}{l}\text { Inst. Fed. - } \\
\text { Tecnólogos }\end{array}$ & Rua & \\
\hline $\mathrm{EF}$ & 173 & & & & 12 & 185 \\
\hline EM & & 211 & 58 & & 10 & 279 \\
\hline ES & & & & 115 & 4 & 119 \\
\hline TOTAL & 173 & 211 & 58 & 115 & 26 & 583 \\
\hline
\end{tabular}

EF: ensino fundamental; EM: ensino médio; ES: ensino superior; Esc. Munic.: escola municipal; EJA: educação de jovens e adultos; Ts: turmas; Esc. Est.: escola estadual; PROEJA: Programa Nacional de Integração da Educação Profissional com a Educação Básica; Inst. Fed.: instituto federal.

3 Também aplicamos questionários nas ruas dos bairros, apenas para contraste. Não serão considerados intensivamente nesta análise.

4 Assumimos coeficiente de significância (alpha) de 0,05. 
No que tange às respostas aos questionários, discutiremos aspectos relacionados ao trabalho, à escolaridade dos respondentes e seus familiares, às bases habituais de informação e navegação indicadas e às preferências relativas ao tempo dispendido na instituição escolar. No que concerne a este último, trabalhamos com opções lançadas no instrumento, ante categorizadas com base em leituras de sociologia da educação e das juventudes, entre práticas tendencialmente "institucionais", "sociáveis-institucionais", "sociáveis" e "divergentes", ainda que, como veremos, a análise assinale articulações distintas em campo.

Já em relação aos grupos de discussão, foram cinco em escolas estaduais, um numa unidade municipal e um em instituto federal ${ }^{5}$, dentre aquelas onde aplicamos os questionários, sendo que cada edição contou com cerca de dez integrantes. A escolha das unidades escolares atendia ao propósito de diálogo com estudantes, considerando níveis de ensino diferentes. A adoção desse procedimento destina-se mais comumente ao conhecimento de experiências sociais dos sujeitos e sua relação com os contextos onde se inserem. Normalmente, é produzido junto a pessoas com vivências ou pertenças em comum, e que inclusive se conhecem (Weller, 2006).

Por fim, selecionamos estudantes para entrevistas narrativas (Jovchelovitch, 2002). Como se pode depreender do referencial adotado e do método delineado aqui, os diferentes percursos narrados que consideramos visavam a compreensão de uma experiência comum. Dessa forma, a última parte da interlocução, em nosso caso, orientava-se a questões temáticas que apoiassem o aprofundamento das narrações no que concerne ao trabalho dos indivíduos no enfrentamento da prova social da escolarização.

Cinco entrevistados foram selecionados dentre aqueles que participaram dos grupos de discussão e se mostraram interessados em seguir em diálogo. Procuramos contemplar os diferentes níveis de ensino e, ademais, ponderar elementos destacados durante a participação na fase precedente, especialmente no que tange à relação dos sujeitos com o desempenho escolar e as "formas de presença" identificadas por intermédio da aplicação de questionários.

\section{JOVENS E ESCOLA}

Particularmente entre os jovens com idade entre 15 e 17 anos, dados da PNAD indicam uma ampliação da escolaridade e do tempo de permanência na escola. Para segmentos historicamente excluídos, o incremento da frequência à escola foi sensivelmente superior entre 2004 e 2014 (2,5\% de forma geral contra $10,6 \%$ para jovens de famílias do primeiro quintil de renda). Isso não altera a recorrência de percursos truncados ao longo da escolarização, com casos de repro-

5 Optamos por privilegiar o Ensino Médio para os grupos de discussão em função da presença massiva de jovens primeiramente. Além disso, o segmento de jovens-adolescentes condiz àquele que tem experimentado o incremento mais significativo no tempo de habitação da escola, segundo análises comparativas de dados da Pesquisa Nacional por Amostra Domicílio (PNAD) (Sposito, Souza e Silva, 2018), o que, para efeito da pesquisa em curso, configura-o como grupo privilegiado para compreensão da escolarização como prova social. 
vações, desistências e/ou adesão a políticas de correção de fluxo. Para esse mesmo período, o percentual de jovens cursando ainda o ensino fundamental era bastante representativo (pouco mais de 30\%) (Freitas, 2016; Sposito, Souza e Silva, 2018). Vale considerar, ainda, que o Censo Escolar indicou uma redução no número de matrículas no ensino médio entre 2016 e 2017 (NuPE/UFPR, 2018).

Os efeitos dos elevados índices de desocupação e informalidade dos últimos anos no Brasil, normalmente com repercussão mais severa entre jovens (IBGE, 2018), podem contribuir ao cenário de evasão escolar. Contudo, se consideramos que se mantém, mesmo assim, um quadro de extensão histórica do acesso à escola e à vivência como estudante entre jovens, cabe discutir como estes produzem suas experiências da escolarização, como sugerem Sposito, Souza e Silva (2018).

Segundo Freitas (2016), se a vinculação ao mundo do trabalho segue predominante, há modulações nas expectativas conforme o nível de escolarização logrado: as avaliações relativas às práticas escolares tendem a ser mais positivas entre estudantes do que entre não-estudantes; a esperança de chegar ao ensino superior se eleva estatisticamente à medida que são vencidas etapas da educação básica, de forma que o segmento com idade entre 15 e 17 anos apresenta três vezes mais chance de pretender chegar à faculdade que aqueles entre 25 e 29 anos. De outra parte, entre os sujeitos com baixa escolaridade (não raro, oriundos de população empobrecida e negra), é mais frequente a valorização da sociabilidade produzida no espaço escolar. De modo geral, entretanto, são comuns as manifestações de insatisfação quanto à pertinência dos conteúdos escolares e às contribuições da escola para a inserção profissional e compreensão da realidade.

Dayrell e Jesus (2016) realçam que, para jovens sob exclusão escolar e suas famílias, o investimento nas práticas escolares é perpassado pelo sentido atribuído às promessas institucionais. O clássico apelo moderno que associa a escola ao futuro se faria atuante, instaurando um jogo de tensões na relação entre estudantes, rotina escolar e condições estruturais de subsistência. Nos depoimentos que analisam, os autores destacam o quanto as valorações positivas em relação à educação se dirigem ao porvir, de forma que o cotidiano escolar carece de alusões, quando não é citado desde a dificuldade de associação dos conteúdos curriculares com a realidade extramuros. Então, a evasão chega a ser justificada mais comumente pela "falta de interesse" do que pela "necessidade de trabalhar".

Se o sentido associado à prática institucional é fraturado pela inviabilidade no espaço de possíveis, potencializando desalento, poderíamos ter em conta um tensionamento da experiência socializadora gestada pela escola, dado que a instituição condensa não só normas de convívio, mas um conjunto de expectativas significantes. Nesse sentido, Dayrell e Jesus (2016) referem também a importância da interação com o professor. A forma de atuação e interlocução estabelecidas pelos docentes com os jovens era citada como base para mobilização do interesse pelas aulas e os saberes, o que faz perguntar pela necessidade de revisão das formas de fruição do presente na escola.

\section{ESCOLA E TRABALHO EM CAMPO: INDÍCIOS DE UM IMPERATIVO}

A desocupação entre jovens é questão no cenário mundial (IBGE, 2018) e, quando observamos as condições de trabalho para o segmento juvenil no Brasil, 
percebemos índices de desemprego e informalidade superiores à média populacional (Corseuil, 2016). Então, se como assinalava Corrochano (2016), considerarmos a configuração de um imperativo do labor como forma de "ganhar a vida" e a percepção do trabalho como necessidade para jovens de baixa renda, poderíamos cogitar a pungência associada às expectativas de trabalho em contextos socialmente vulnerabilizados. Nesse sentido, Zago (2011) já trazia inferências sobre a inter-relação entre possibilidades laborais e expectativas de escolarização em meios populares, ora indicando desejos familiares de mobilidade social, ora tensionando a obrigação escolar.

A mãe botou sempre bastante ordem, assim. Eu digo que não tive infância porque eu nunca fui uma pessoa de sair pra brincar com amigos, sabe? Essas coisas assim, sempre fui dentro de casa, sempre fui muito caseira assim. Ai eu arrumava minhas coisin has, minhas bonecas assim sabe? Arrumava, brincava e ai já era hora de guardar pra fazer os temas, sabe? [...]

E tipo eu sempre aprendi a ser forte, sabe? Tipo, com todas as minhas perdas eu sempre, claro, a gente não é maduro o suficiente nunca pra nada, mas eu sempre aprendi a ser forte. Esse ano que eu tô bem abatida assim, mas tô trabalhando. Graças a Deus, tô recebendo bastante!

Minha mãe tem o restaurante há uns sete anos, então desde quando começou, eu sempre ajudava ela, uma coisinha ou outra. Agora eu trabalho mesmo [...] Agora construi minha casa, é nos fundos da minha mãe, mas é minha. Minha casa e meus dois bichinhos. (Camile 616 anos, segundo ano EM noturno, jul. 2019)

Nossos interlocutores indicavam que, conforme as condições materiais familiares, o imperativo poderia se acentuar e/ou combinar demandas por autonomia. Parece ser bastante disseminado para as ambiências de periferia que abordamos, entretanto, a convocação ao trabalho, a premência de produzi-lo por necessidade ou para fruição do consumo, articulava-se, de forma mais ampla, a um imperativo moral por independência e responsabilização no enfrentamento das adversidades dispostas aos sujeitos. Ao comentar os esforços e "superações", as narrativas informavam um código para tomada de posição frente à primordial prova social, configurada na tarefa individual, e herança moderna, de produção da própria existência, de criar condições para sua consecução no mundo.

Ao considerarmos especificamente os jovens estudantes, temos, porém, uma inflexão a observar. $\mathrm{Na}$ maioria dos casos, temos sujeitos que ampliaram a escolaridade e a habitação da escola, se comparados a seus ascendentes, em congruência com os dados da Pesquisa Nacional por Amostra de Domicílio (PNAD) citados acima. Cerca de $60 \%$ não estavam trabalhando no momento em que responderam aos questionários e 33\% nunca tinham trabalhado, dedicando-se sobretudo à frequência escolar.

6 Os nomes utilizados para referir nossos interlocutores ao longo do texto são fictícios. 
Aqui, temos uma situação relativamente complexa a seguir analisando. De um lado, as entrevistas indicam que os jovens em condição mais empobrecida realizavam atividades de trabalho informais, apoiando-se em redes parentais e de amizade, mas que, via de regra, eram ocupações de curta duração. De outro, haveria aqueles que não teriam experienciado inserções ao mundo do trabalho. Os depoimentos sinalizavam, nesse caso, que sua permanência na escola se devia ao esforço dos coletivos familiares, que passaram (ou puderam passar) a priorizar a escolarização da prole. Nesses arranjos, percebemos que os os filhos menores tendiam a se privilegiar mais, dado que os mais velhos seriam aqueles mais regularmente convocados aos serviços doméstivos ou ao apoio no custeio familiar.

Eu vim de uma família humilde, com oito irmãos. Acho que minha infância foi bem legal até. Até que a gente não cresceu com tanta dificuldade assim, sabe? Até porque os meus irmãos eles sempre foram bem independentes assim, então pra mim não foi tão ruim assim, não pesou tanto, mas graças a Deus! [...] O mais velho ele trabalhava numa lavagem de carro, que ele tinha montado com um amigo dele. A segunda mais velha é doméstica. Os outros dois, um jogava futebol e tinha empresário, e o outro trabalhava numa empresa de ônibus. E eles ajudavam [...]

Minha mãe sempre incentivou a gente a estudar, porque ela não teve bastante estudo, ela foi até a terceira série. Meu pai também só acabou o fundamental e foi até o segundo ano do ensino médio. Os outros irmãos todos eles não completaram também, então os mais novos ela quis investir bastante nos estudos.

Agora não tô trabalhando. Durante o dia eu ajudo a minha mãe nas tarefas da casa, depois eu converso um pouco com a minha namorada pelo telefone, de tarde eu acabo ajudando meu padrasto na construção da casa. Quero trabalbá pra ter minha casa. Quero morá sozinho. (Samuel, 17 anos, terceiro ano EM noturno, jun. 2019).

A composição de uma rede de proteção e promoção de crianças e adolescentes, e os programas governamentais que se seguiram aos anos 1990 e 2000, com maior atenção às juventudes, têm concorrido para a produção social de tempos de infância e de juventude, em que pese a insuficiência e a precariedade com que se efetivam no atendimento às classes populares (Sposito, 2008). Segundo narram, nossos interlocutores experienciariam arranjos familiares que preservaram a infância e a escolarização (mesmo que intermitente), embora houvesse responsabilização doméstica em muitos casos. Aí, a juventude se constituiria pela demanda ao trabalho, mas privilegiando a conclusão da educação básica.

De outra forma, evocando as análises de Lahire (1997), há uma forma de mobilização familiar em jogo. Observamos a permanência do imperativo moral aludido; ainda que a socialização por ingresso no mundo do trabalho seja postergada, certa disposição ao "dever" parece se constituir nas demandas familiares, associado à contrapartida do suporte recebido e à necessidade de independência frente a possíveis adversidades. Lá estaria a responsabilização por tarefas domésticas e de cuidado ou, de outra parte, a própria escolarização, versada não só como signo de melhoria das condições de vida, mas como a parte que cabe ao jovem nos esforços 
cotidianos. Trabalho e escolarização, que podem concorrer nas priorizações cotidianas, aproximar-se-iam axiologicamente na narração dos desafios afrontados.

Por outro lado, no entanto, a ampliação da permanência na escola e, com isso, do convívio com pares, não se dá sem constituir disputas nos processos de individuação juvenil. A instituição escolar tem configurado parte da moratória social destinada e formadora da juventude (Margulis e Urresti, 1996). Entendemos que se potencializa, ali, a vivência da condição juvenil, na fruição do tempo reflexivo e de não-trabalho, nas trocas sociáveis entre colegas, na possibilidade de partilha de consumos culturais.

Se não podemos falar, aqui, por uma condição cultural de classe, da tendência ao "crepúsculo do dever" na forma como afirma Martín-Barbero (2017) ao evocar a análise de Gilles Lipovestisky sobre o capitalismo contemporâneo, é preciso atentar também para dinâmicas específicas que se formam na relação entre juventudes e escola nas periferias, a luz do que já vem indicando a sociologia das juventudes (Dayrell e Carrano, 2014; Pereira, 2016).

\section{NA ESCOLA, REFLEXÕES SOBRE AS FORMAS DE PRESENÇA}

Ainda que as promessas institucionais figurem com importância e situem a instituição escolar desde uma mirada ao porvir nos itinerários biográficos, a literatura sinaliza para sentidos diversos do espaço escolar entre os grupos populares. Mesmo que o trabalho configure muito das expectativas familiares, a associação da escola à segurança-proteção ou a programáticas socializadoras morais também compõem a relação com a instituição (Zago, 2012). Mais além, as pesquisas sobre juventudes têm salientado a importância das práticas culturais (artísticas e esportivas) e das relações de sociabilidade no cotidiano e nas produções identitárias juvenis (Dayrell, 2007; Dayrell e Carrano, 2014), incidindo sobre a rotina escolar. Dubet e Martuccelli (1998) já salientavam que, entre os jovens, a referência do mestre se esmaecia quando os alunos passavam a compor suas experiências também em articulação ao universo cultural juvenil e às interações entre pares.

Nesse sentido, Pereira (2016) procura problematizar justamente a imbricação entre experiências juvenis e estudantis, tomando uma abordagem etnográfica em escolas públicas das periferias de São Paulo. Observa o autor que os jovens interpõem ritmos diversos à disciplina escolar e ao controle de tempos e espaços a ela vinculados. A fruição do tempo entre pares, no consumo cultural, nas interações por redes sociais ou nas dinâmicas de conversação e "zoeira" disputariam o espaço da escola e criariam dissonâncias com o mundo adulto. Pereira (2016) parece perguntar não por uma realidade "fraturada", mas pela interface entre ritmos dissonantes, sem, no entanto, considerar possíveis situações de interpenetração entre ritmos e práticas nas disputas pelo fazer escolar.

Seguindo essa perspectiva, aventamos que a realidade escolar precisa ser compreendida a partir de sua articulação à produção das culturas juvenis. Em tal relação tensa e truncada, enfim, entendemos que cabe problematizar formas de presença produzidas no cotidiano e que rearticulam conexões com o espaço escolar, ou, por outras palavras, tomar o "trabalho dos indivíduos" na habitação da escola e na relação com o que agenciam na produção da experiência naquele locus. 


\section{PARA COMEÇAR...}

Cabe observar, de início, as condições em que se dão as relações com a escola, enlaçando alguns das inferências consolidadas na literatura. Primeiramente, as informações que sistematizamos via questionários indicam associação entre escolaridade do respondente e a designada para "mães" e "pais", lembrando a clássica tese da herança cultural (Bourdieu, 1999). Constatamos que a situação de escolarização mais extensa era acompanhada da sinalização de carreira escolar mais avançada para a mãe e o pai, com destaque para a primeira, embora tendencialmente inferior à do jovem aluno consultado. Então, para aqueles que cursavam o ensino fundamental à época da consulta, os responsáveis teriam deixado a escola sem completar essa mesma etapa, ao passo que, com menor intensidade, o mesmo ocorria para os que estudavam no ensino médio. Da mesma forma, além disso, a escolaridade dos tios também teria associação significativamente positiva, o que não ocorria, porém, quando tomávamos registros sobre a condição escolar dos avós, que especialmente os estudantes do ensino fundamental desconheciam inclusive (37,3\% no total contra $56,3 \%$ para o grupo referido, no caso da vó materna, por exemplo).

As informações acima parecem concernir à ampliação histórica do acesso à instituição escolar no Brasil (Brasil, 2000; IBGE, 2018), mas nos levam a considerar também que a relação com a escolarização está articulada à rede de interdependências presente nas dinâmicas familiares, na forma como sugere Lahire (1997). A referência mais recorrente à escolaridade da mãe $\mathrm{e}^{7}$, junto à correlação com a condição dos tios, pode ser signo do que aventamos. O fato da carreira escolar dos avós ser pouco conhecida nos leva a crer, por outro lado, que, se o domínio do capital cultural preconizado pela escola opere objetiva e comparativamente em favor da carreira escolar, os sentidos da instituição são compreendidos nos moldes de uma herança familiar à medida do êxito dos sujeitos e seus entes próximos no sistema educacional.

Tomando tal hipótese acerca da valoração simbólica da escola, consideramos uma aproximação, de resto, com o cenário de crescente expectativa em relação ao sucesso escolar dos mais jovens em famílias de camadas populares, tal como assinalado por Cabanes $(2006)^{8}$ para a realidade de São Paulo, por efeito das agências que fomentam o acesso à escola desde o início do período democrático institucional. Contexto que faz perguntar pelo lugar das tensões e dissonâncias mencionadas

7 Entre os respondentes, 7,8\% para a "mãe" e 16,1\% para o "pai” afirmavam "não saber" ou "não se aplicar" como pessoa de referência ao longo do itinerário. Dado semelhante foi observado na pesquisa analisada por Dayrell e Jesus (2016), indicando ainda a realidade familiar diversa, cujos arranjos tendem a contar com a presença da mãe, mas podem também ser compostos somente por avós e ter outros parentes que apoiem, observando-se, ainda, a frequente ausência paterna.

8 A necessidade de discutir as redes de interdependência e as expectativas familiares como dispositivos relacionados à mobilização simbólica ao êxito escolar (além da ampliação de acessos por políticas públicas) concerne também as outros dados. A associação indicada entre as escolaridades dos responsáveis e do respondente não mantém a mesma proporção entre alunos dos cursos tecnólogos, quando muitos registram ensino fundamental completo ou incompleto para pais e mães. 
antes na interação com buscas por sentidos e condições de coprodução do tempo dispendido na escola.

\section{INTERNET, ESCOLA E INTERATIVIDADE}

Até esse ponto, a problematização nos invita a considerar conjuntamente a ampliação histórica de acesso (especialmente à educação básica), condições de origem desiguais e experiências truncadas de escolarização e, além disso, sentidos construídos no quadro da virtualidade socializadora moderna, com destaque às expectativas de trabalho, mobilidade social e independência. Quando nos atemos ao cotidiano na instituição escolar, ao tempo presente da ocupação daquele locus, há aspectos a examinar que, concernentes a tal cenário, podem nos encaminhar a nuances na interpretação.

Para efeito dessa análise, gostaríamos de dedicar atenção a certa propensão interativa que se indicia nos dados que produzimos em campo. Referimo-nos aos usos cotidianos de mídias sociais. Quando convidados a indicar os meios mais utilizados para busca de informações, os respondentes registraram principalmente "Internet" (em 90\% dos casos) e "TV" (61\%). Na Internet, os mais acessados seriam: "redes sociais" (79\%), "músicas" (42,4\%), "filmes" (35\%), "conteúdos de estudo" (34,2\%), seguidos de "séries" $(24,3 \%)$ e "jornais eletrônicos" $(23,9 \%)$. Parece predominar interação e entretenimento, com usos mais escassos para consumo de conteúdos escolares ou narrativas jornalísticas. Já na TV, o mais recorrente era a citação de "filmes" (58\%), "noticiários" (51\%), "novelas" (39\%), "séries" (37\%) e "programas esportivos" (25\%). Aqui, novamente o entretenimento se destaca entre as citações.

Para quem acessa regularmente o espaço escolar, ou mesmo por uma observação do cotidiano de forma geral, talvez seja possível depreender empiricamente os usos amplamente disseminados da Internet e das redes sociais (sobretudo via celular). Kubota (2016) indicava igualmente uma apropriação crescente dessas tecnologias à medida que nos dirigimos a extratos mais jovens ( 16 a 24 anos especialmente), com predomínio de interatividade e entretenimento (redes de relacionamento, filmes, música, jogos etc.). A procura por emprego ou alternativas de ensino figurariam com mais destaque com a elevação da idade. Da mesma forma, o acesso à internet, a redes sociais e a celulares para tal uso seria superior entre jovens conforme ampliam-se a renda e a escolaridade destes.

Para a amostra em análise, aqui, quando ponderamos "tempo dedicado à escola" e "frequência de acesso à Internet", percebemos que entre os não-estudantes (em geral, adultos) o acesso à internet se mostrava distribuído entre as opções de tempo de dedicação (30,8\% para "permanece conectado" e 23,1\% para "não acessa", por exemplo), ao passo que aqueles que tinham tempo regular na escola concentravam-se em "permanece conectado" (56,4\%). Relacionando "frequência de acesso à Internet" e "escolaridade" do respondente, percebemos um aumento de 19 pontos percentuais do EF para o ES. O "acesso à internet" também aumenta progressivamente junto com os "anos de estudo" acumulados (26,3\% para " 4 a 7 anos" e $68,2 \%$ para " 15 anos ou mais"). Dado que "anos de estudo", da forma como o computamos, presta-se a indicar a duração da habitação da escola no itinerário (e não uma progressividade associada à escolaridade) (IBGE, 2017), essa informação convida a uma ponderação 
importante: possivelmente, não só o progresso na escolarização influiria nos usos da internet, mas também a permanência na instituição escolar, o que nos faz aventar efeitos da interação entre pares.

Outro dado significativo, se "Internet" e a "TV" são as principais fontes de informação citadas, o "tempo para busca de informação" por si tem muitas citações de "não se aplica". Cabe considerar que tal arranjo se deva ao fato de ambas serem mais utilizadas para interatividade e/ou entretenimento. Faz pensar, além disso, que a ampliação dos usos da internet junto à escolarização não estaria associada necessariamente a uma apropriação informacional-estudantil, mas a uma tendência interativa e sociabilizante 9 .

Entretanto, por ocasião dos grupos de discussão realizados, os relatos mencionavam a intersecção de práticas escolares e usos de mídias. Contavam que quando tinham tempo sobrando em aula, acessavam redes sociais ou escutavam música ${ }^{10}$. De outra forma, se a aula fosse considerada tediosa, também poderiam usar os celulares para distração. Ademais, se a fruição das mídias compunham a rotina escolar, elas também apoiavam a realização das atividades como aluno, dado que havia grupos ou comunidades online para informar sobre tarefas e provas, incluindo ações astuciosas como a veiculação de "colas" para momentos de avaliação.

Então, mesmo que se observe dissonâncias ou mesmo ruptura da temporalidade institucional, acreditamos ser mais pertinente não tomar as táticas de jovens estudantes como indicativo de uma cisão entre a condição juvenil e o ofício de estudante. Para além de lembrar a articulação entre a produção sócio-histórica da juventude e moratória social concernente, em boa medida consequente da instituição de tempo social para habitação da escola (Margulis e Urresti, 1996), por ora, parece-nos que cabe uma aproximação aos resultados da pesquisa de Souza e Leão (2016), que indicavam uma mútua afetação tensa entre ser jovem e ser aluno nas interações online. Nas palavras dos autores:

Outro elemento que nos chamou atenção foi o fato de que os alunos ao mesmo tempo que rejeitavam o ofício de aluno na sala de aula o reproduziam no espaço on-line [...] esse reforço ou reprodução do trabalho de aluno em rede, alertou-nos para outros elementos que atravessavam tal ofício e que são marcas

9 Reforça tal argumento a semelhante predominância de opções relativas à interatividade e entretenimento mesmo para alunos de cursos de graduação que consultamos. Por exemplo: 83,9\% dos alunos de EF citaram “redes sociais" e 82,1\% o fizeram entre alunos dos tecnólogos.

10 Entendemos que a apropriação da música particularmente, não é mera distração. Ao contrário, diz respeito à organização da experiência, agindo sobre a temporalidade construída pelos jovens. Uma citação de Martín-Barbero (2008) pode ser elucidativa: "A juventude encontrou modo de organizar, ou melhor, de dar forma ao amorfo tempo do ócio/sem trabalho, desdobrando-o ritmicamente para erradicar sua chateação intrínseca. E nenhum outro cadenciador é melhor que a música, pois ela mesma é uma organização abstrata do tempo e revelação da mais profunda especificidade do estético: a música é aquela tecnologia que permite fazer desenhos abstratos de temporalidade experimental" (Martín-Barbero, 2008, p. 16). 
próprias dos jovens-alunos, hoje midiatizados: o tempo do fazer escolar não linear, a maior prática da coletivização do trabalho escolar, a intensificação das trocas de aprendizagens, a diversificação das formas de acesso aos conteúdos escolares. (Souza e Leão, 2016, p. 299)

\section{ESCOLHAS NO COTIDIANO ESCOLAR}

Passando a elementos apreciados nos momentos experienciados no interior da escola segundo os estudantes, os itens mais citados em resposta aos questionários nos conduzem à sociabilidade entre pares ${ }^{11}$. Frente ao cruzamento entre "nível de ensino" e "elementos apreciados na escola" (vide Tabela 2), percebe-se que "momentos junto a colegas" tem predominância em todas as etapas. De outra parte, "aulas de alguns professores" se dispõe sempre como segunda opção mais citada. Quando tomamos respondentes em cursos de ensino superior (tecnólogos), se observa uma leve tendência à aproximação de "conteúdo de alguma disciplina", além de que "diálogo com professores" supera "tempo no intervalo".

Tabela 2 - Distribuição de elementos apreciados na escola conforme
nível de ensino/escolarização em curso: múltipla escolha.

\begin{tabular}{l|c|c|c}
\hline Alternativas & $\begin{array}{c}\text { Ensino } \\
\text { fundamental }\end{array}$ & $\begin{array}{c}\text { Ensino } \\
\text { médio }\end{array}$ & $\begin{array}{c}\text { Ensino } \\
\text { superior }\end{array}$ \\
\hline Momentos junto a colegas & $70 \%$ & $57,1 \%$ & $72,2 \%$ \\
\hline Atividades no intervalo & $33,3 \%$ & $29,9 \%$ & $26,9 \%$ \\
\hline Zoação com colegas & $23,3 \%$ & $23,4 \%$ & $18,5 \%$ \\
\hline Passeios organizados pela escola & $23,3 \%$ & $33,8 \%$ & $23,1 \%$ \\
\hline Aulas de alguns professores & $56,7 \%$ & $51,9 \%$ & $67,6 \%$ \\
\hline Tempo no laboratório de informática & $10 \%$ & $7,8 \%$ & $14,8 \%$ \\
\hline Conteúdo de alguma disciplina & $30 \%$ & $33,8 \%$ & $50 \%$ \\
\hline Tempo na biblioteca & $16,7 \%$ & $5,2 \%$ & $11,1 \%$ \\
\hline Diálogo com professores & $16,7 \%$ & $26 \%$ & $27,8 \%$ \\
\hline
\end{tabular}

11 Para que possamos situar nosso entendimento acerca da "sociabilidade", as contribuições de Simmel (2006) são centrais. Para ele, a sociabilidade se define como a "a forma lúdica de sociação" (Simmel, 2006, p. 65). Nela (em sua forma pura), acentua-se a inter-relação entre os indivíduos e designaríamos aquelas situações em que as interações ganham sentido em si mesmas, no jogo das relações entre indivíduos no ato de "entreter-se". O conteúdo das conversas sociáveis deve ser significativo e cativante, articulado a outras dimensões da vida, mas não submetida a elas no momento de sua fruição. Na sociabilidade, o "jogador" inscreve-se atraído pela dinâmica e pela relativa aleatoriedade dos resultados. 
Percebemos, com isso, a manutenção de uma interação sociabilizadora nos diferentes níveis de ensino, com uma gradual aproximação a elementos que denotam o convencional papel da instituição escolar se nos situamos no ensino superior. Embora haja um redimensionamento da proporção dedicada a itens associados à sociabilidade conforme avançam escolarização e idade, com possível institucionalização rumo às buscas por capital cultural, "momentos com colegas" permanecem inclusive quando se observa diferentes estabelecimentos de ensino.

Se tomamos a distribuição dos "elementos apreciados na escola" por local de preenchimento, a constante é "momento junto a colegas", sendo o mais citado e com manutenção do mesmo percentual (por volta de 66\%). Vejamos, porém, algumas nuances: nas escolas estaduais, onde aplicamos questionários junto a jovens do ensino médio, os itens "tempo no intervalo", "zoação com colegas" e "passeios organizados pela escola" têm expressão quase equivalente (em torno de $43 \%$ das citações), em segundo lugar de prioridade. Nas unidades municipais, com alunos de EF/EJA, a segunda opção mais referida foi "aulas de alguns professores" $(56,3 \%)$, seguida de longe por "atividades no intervalo" $(34,4 \%)$ e "conteúdo de alguma disciplina" (31,3\%). No instituto federal, com alunos de PROEJA e cursos superiores tecnólogos, "aula de alguns professores" foi a segunda escolha (63,5\%, muito próxima de "momentos junto a colegas"), seguida de "conteúdo de alguma disciplina” (47,1\%).

Podemos dispor algumas constatações nesse sentido. Acentuar-se-ia a preferência por opções associadas à dinâmica institucional educativa se adentramos iniciativas vinculadas à profissionalização, mantendo, ainda assim, a importância da interação com colegas e da relação com o saber mediado pelo professor. As unidades municipais e estaduais aqui referidas parecem apresentar sinais de tensão na relação com os alunos, de forma que as preferências se encaminham para itens que sugerem interlocução pessoal e/ou ruptura dos ritmos escolares. Para os alunos de EF/EJA, a mediação do professor indica-se como particularmente significativa. De sua parte, por fim, os cursos superiores têm o ingresso regulado por exames, o que segrega já de início desde o domínio de capital cultural, de forma que entre os alunos encontramos moradores de bairros mais abastados ou mesmo de outras cidades.

Assim, cabe aventar que as nuances para aproximação à dinâmica institucional educativa variam conforme os estabelecimentos de ensino. De maneira mais específica, segundo a precarização da infraestrutura e as condições de trabalho do corpo docente ${ }^{12}$, os métodos de ingresso adotados e a possível associação ao mundo do trabalho. Esta última é recorrentemente citada pela literatura (Dayrell

12 Aqui, cabe uma observação registrada em diário de campo. Por conta da visita às escolas para aplicação dos questionários, era facilmente perceptível as diferenças qualitativas quanto à infraestrutura física dos estabelecimentos de ensino, em detrimento das escolas estaduais primeiramente, mas também das unidades municipais. $\mathrm{O}$ mesmo vale para condição de trabalho docente. A rede estadual de ensino apresenta condições severas de precarização, incluindo salários comparativamente inferiores (às redes municipal e federal) e, nos últimos anos, o parcelamento no pagamento destes. 
e Jesus, 2016; Freitas, 2016). Outrossim, para os grupos mais vulnerabilizados, no caso, alunos de EF/EJA especialmente, a presença na escola muito atentaria para a sociabilidade (com colegas e professores).

Encaminhando-nos ao final de nossas problematizações nesse tópico, trataremos da articulação verificada entre os "elementos apreciados na escola", de modo a categorizar "formas de presença" no espaço escolar associadas ao que apresentamos até aqui (conforme Tabela 3). Quem registrou "tempo no intervalo", tendeu a optar por "momentos com colegas" (71,6\%) e, com menor ênfase, "aulas de alguns professores (33,8\%). Nesse caso, vale destacar, porém, que este é acompanhado de perto por "zoação com colegas" e "passeios" (ambos com 29,7\%). A partir desse ponto, sinalizamos para a primeira forma, que denominaremos como sociável-convergente.

Tabela 3-Agrupamento de elementos apreciados na escola.

\begin{tabular}{|c|c|c|c|c|c|c|c|c|c|}
\hline 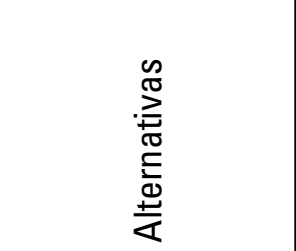 & 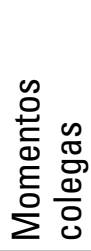 & $\begin{array}{l}\frac{0}{\pi} \\
\stackrel{2}{\frac{1}{d}} \\
\stackrel{ \pm}{ \pm} \\
\underline{\leq}\end{array}$ & 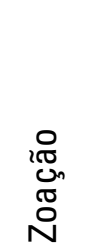 & 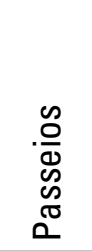 & $\begin{array}{l}\frac{n}{4} \\
\frac{0}{2} \\
\frac{2}{0} \\
\frac{\pi}{3} \\
\frac{1}{4}\end{array}$ & 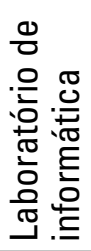 & 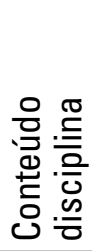 & 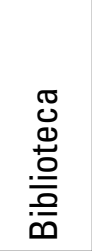 & 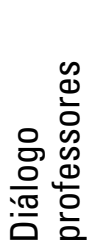 \\
\hline Momentos colegas & $100 \%$ & $71,6 \%$ & $77,6 \%$ & $65,2 \%$ & $59,9 \%$ & $60 \%$ & $51,9 \%$ & $56 \%$ & $49,2 \%$ \\
\hline Intervalo & $33,3 \%$ & $100 \%$ & $44,9 \%$ & $33,3 \%$ & $17,6 \%$ & $16 \%$ & $14,8 \%$ & $28 \%$ & $9,5 \%$ \\
\hline Zoação & $23,9 \%$ & $29,7 \%$ & $100 \%$ & $24,2 \%$ & $14,8 \%$ & $16 \%$ & $3,7 \%$ & $4 \%$ & $6,3 \%$ \\
\hline Passeios & $27 \%$ & $29,7 \%$ & $32,7 \%$ & $100 \%$ & $20,4 \%$ & $36 \%$ & $14,8 \%$ & $24,0 \%$ & $7,9 \%$ \\
\hline Aulas de alguns professores & $53,5 \%$ & $33,8 \%$ & $42,9 \%$ & $43,9 \%$ & $100 \%$ & $56 \%$ & $63 \%$ & $72 \%$ & $66,7 \%$ \\
\hline Laboratório de informática & $9,4 \%$ & $5,4 \%$ & $8,2 \%$ & $13,6 \%$ & $9,9 \%$ & $100 \%$ & $9,3 \%$ & $8,0 \%$ & $7,9 \%$ \\
\hline Conteúdo disciplina & $35,2 \%$ & $21,6 \%$ & $8,2 \%$ & $24,2 \%$ & $47,9 \%$ & $40 \%$ & $100 \%$ & $44 \%$ & $52,4 \%$ \\
\hline Biblioteca & $8,8 \%$ & $9,5 \%$ & $2 \%$ & $9,1 \%$ & $12,7 \%$ & $8 \%$ & $10,2 \%$ & $100 \%$ & $7,9 \%$ \\
\hline Diálogo com professores & $19,5 \%$ & $8,1 \%$ & $8,2 \%$ & $7,6 \%$ & $29,6 \%$ & $20 \%$ & $30,6 \%$ & $20 \%$ & $100 \%$ \\
\hline
\end{tabular}

Se examinamos a escolha por "zoação com colegas", reforça-se sua vinculação com "momentos com colegas" (77,6\%) e "atividades no intervalo" (44,9\%). Interessante observar que, mesmo nesse caso, o item "aulas de alguns professores" está presente de forma significativa (42,9\%). Já os que selecionaram "aulas de alguns professores" (item constante, junto a "momentos com colegas") inscreveram recorrentemente "momento com colegas" (59,9\%), "conteúdo de alguma disciplina" $(47,9 \%)$ e, mais atrás, "diálogo com professores" (29,6\%). Aqui, desenham-se outras duas formas de presenças: a primeira, designamos sociável-tensionadora; a segunda, definimos como sociável-institucional, dada sua aproximação a elementos da dinâmica escolar, mas que nem por isso é menos ciosa de interação e sociabilidade. A constituição desta última forma nos parece reforçada pelas escolhas associadas a "conteúdo de alguma disciplina", "tempo na biblioteca" e "diálogo com professores". 
Por certo, a classificação que expomos acima não tem o fito de ser exaustiva ou extrapolável. Apenas exercitamos um delineamento para pesquisas futuras. Apesar dos limites, entendemos que um aspecto importante a explorar concerne à regular articulação entre elementos institucionais e sociabilizantes nos agrupamentos. Consideramos que, provavelmente, as formas de presença, embora indiciem modos de atuação moduláveis no processo de escolarização, organizam-se desde relações tensas e não exatamente cisões. Ou, de outra forma, as dinâmicas sociáveis juvenis e a interação virtual compõem as formas de fruição do escolar, ainda que sob variações segundo as condições objetivas de acesso à instituição.

Na escola, eu tava pelo social. Aprontava, ficava só fundo da sala. Mas... sei lá, os professores percebiam que respeitava eles também. Sabe, aprontava e ia pra direção, ai conversava com a professora e ficava tudo bem. Me dava bem com os profes, gostava de conversá com eles também [...]

Ai, depois, tentei fazê Direito, mas desisti. Não gostei. Não era pra mim. Ai, saí e fiquei um tempo sem estudá. Trabalhei, viajei... Tentei o Direito de novo dali um tempo, mas não deu. Minha cabę̧a tinha mudado. Ai, decidi fazê o curso que eu tô agora. Precisava me prepará e estudei por mim, assim. Usei muito vídeo do Youtube. Bah, tenha muita coisa boa no Youtube. (Ênio, 29 anos, terceiro semestre - ES, set/2019)

Alguns dos aspectos trazidos nos grupos de discussão podem nos ajudar a compreender a potência das dinâmicas sociáveis e interativas na experiência da escolarização e/ou a articulação entre práticas juvenis e estudantis. Segundo nos contaram, o gosto pelos intervalos das aulas se associava à possibilidade de circulação e às múltiplas conversações que podiam estabelecer. E é preciso resgatar Simmel (2006) nesse ponto, de modo a observar a "conversa sociável" desde os jogos que instaura. As participações locutórias não prescindem de protagonismo e lançam os sujeitos à excitação de sutis inesperados, ao mesmo tempo que, para sustentar-se, necessitam garantir que a integração dos interlocutores seja mantida. Trata-se de um jogo lúdico de trocas em que a presença do outro e sua singularidade precisam ser considerados no equilíbrio das interações ${ }^{13}$.

Conforme observamos, tal tipo de performance narrativa e sociável se estende às interações em redes sociais. Artifícios de expressão das emoções que simulam trejeitos faciais (de que os emoticons seriam exemplos conhecidos), assim como certas

13 Tomemos um exemplo. Estávamos no pátio de uma unidade educacional e, juntos de nós, alguns jovens conversavam sobre suas façanhas em jogos de futebol. As narrativas que os jovens partilhavam eram sobre dribles, e carregavam apreciações de desempenho (em geral, de êxito). Então, um dos garotos contava o quanto fazia gols em determinado jogo. Dizia estar "gastando", como quem indicava bons resultados. A performance narrativa procurava exaltar o feito e a habilidade e, para isso, carregava signos metonímicos. Em certo momento, o interlocutor chegou a levantar para encenar seus movimentos, quando da "caneta" (drible) que teria dado em jogador rival. A fala explicava: "ele veio de frente e eu só dei assim (movendo as pernas). Aí, ele fechou e eu "tchau", tava longe (acenando com a mão)". 
apropriações criativas que tensionam o formato textual (em abreviações ou uso de imagens) traduzem a dinâmica da sociabilidade, carregada por tom linguajeiro.

Então, passando a práticas institucionais propriamente, os jovens-estudantes assinalavam que a própria qualidade das aulas que frequentavam era alvo de apreciação, tomando o nível de implicação dos professores com as experiências dos jovens, de forma que, sem se negar o "dever" suposto de aprender os conteúdos ou do êxito escolar, reivindicavam que os mesmos fossem dispostos interativamente. Em um dos grupos de discussão, dizia uma jovem estudante: "se todos os professores fossem que nem o André, que vira as costas e enchi o quadro, a escola tinha terminado. Tem que conversá com a gente, dá exemplo”.

As narrativas dos jovens em campo indicavam que, não raro, a temporalidade escolar, a relação racional e sequencial com o conhecimento era tensionada via fragmentação e conectividade, interpondo interatividade online ou fruição musical nos interstícios do controle professoral. Contudo, entendemos que, em associação a isso, há uma preferência dissímil na relação com os saberes que percorre as diferentes formas de presença. Abaixo, dispomos citações de entrevistas de estudantes a priori situados distintamente em nossa categorização.

Minha mãe, ela ficava tipo: "filha, tu foi bem, isso é incrivel, mas tu pode ir ainda melhor! [...] Eu, com seis anos, comecei a estudar música. Não foi meu primeiro acesso à cultura, mas foi a primeira vez que eu fui estudá, né. Então, eu comecei a tocá flauta e logo eu fui pra flauta transversa e junto eu já tocava piano [...]

Eu gosto de ler, mas eu gosto principalmente de ouvir, então eu ouço e tento ver o que eu aprendi e tento passar pra alguém o que eu aprendi. Ai eu vejo o que eu preciso passar que eu aprendi, nunca é exatamente [...] Faço isso com o pessoal do grêmio, faço eles de cobaia [risos]. [...] Eu aprendo bem mais nessa dinâmica de conversar com as pessoas do que estudando sozinha. Quando a escola pede alguma coisa e eu não tenho vontade de aprender aquela coisa, eu decoro aquela coisa. E as vezes nem precisa, né, porque sempre rola aquele disfarcezinho [sinalizando para a manga da blusa, como tivesse uma "cola” ali]. (Marja, 17 anos, terceiro ano - Ensino Médio diurno, jun/2019)

O trecho acima é de interlocução com uma estudante atuante no grêmio, cuja jornada diária era narrada desde intensas atividades no interior da escola e no movimento estudantil. Apresentava bom resultados nas atividades institucionais e, além disso, demonstrava conhecimento relativamente crítico à rotina escolar em sua entrevista, apoiando-se em categorias usuais aos docentes em suas explicações. O domínio de capital cultural construído com apoio do quadro familiar, mas também em sua imersão política, não a distanciava de astúcias compensatórias aos desacordos com as prescrições institucionais. Da mesma forma, não dirimia sua adesão a modos interativos e interlocutórios de relação com o saber. Tomemos mais dois exemplos:

Ai, na escola, tipo eu não pego muito, a não ser prova ou coisa assim, mas eu não pego muito pra ler fora da escola, primeiro porque eu não tenho tempo e, segundo, porque me dá sono, sabe? Por isso que eu presto bem atenção na aula, principalmente em exemplos assim, exemplos que professores falam que fica na cabeça. Eu gosto de per- 
gunta e resposta, tipo, ah dos exercícios, sabe, que eles passam. Quando não passam, é complicado, porque ler... Eu não consigo lembrar direito [...]

Gosto de professor que explica! Explica e dá bastante exemplo. Comparar, sei lá, um pato com Física, sei lá, eu gravo aquilo. (Camile, 16 anos, segundo ano EM noturno, jul. 2019)

Eu só vejo o que vai cair na prova. Se o professor deu as matéria eu tenho no caderno, ai vou lá, passo o olho por cima e vou fazê a prova, e normalmente dá certo. Não é uma coisa que é um perigo, ah, ter que sentá três horas pra estudá e depois tirá uma nota boa. (Gilson, 27 anos, T5 EF/EJA noturno, jun. 2019)

Esses dois casos narraram situação de intenso e simultâneo envolvimento com trabalho durante escolarização, sendo que o segundo relatou um itinerário perpassado por precariedades materiais e ocorrências de violência, tendo uma trajetória escolar intermitente. Diferiam nas formas de presença mais recorrentes ao longo da escolarização, sociável-convergente e sociável-tensionadora respectivamente, ainda que Gilson buscasse priorizar a conclusão do ensino fundamental no período recente, quando de nossos diálogos. No entanto, poderíamos observar aspectos em comum no que tange à relação com os saberes privilegiados pelos professores. De uma parte, ambos demonstram ter construído certa familiaridade com a rotina escolar e com o jogo de prescrições e demandas avaliativas dos professores, de forma que procuram um modo preparação que atenda a uma obrigação estabelecida. De outra, há uma preferência enunciada, assim como para Marja, de performances docentes apoiadas na oralidade, na interlocução e nos exemplos para que o êxito seja alcançado.

Se podemos aventar uma associação aos diferenciais de domínio de capital cultural nos casos acima, cabe cogitar também os efeitos da habitação da instituição, na forma de uma experiência de suas prescrições e expectativas, que articula outras referências e recursos como suportes. As formas de presença poderiam sinalizar, então, tomadas de posição na coprodução da escolarização.

\section{PARA SEGUIR... IMPERATIVO, ESTÉTICA E INDIVIDUAÇÕES NA ESCOLA}

A atuação dos jovens-estudantes com quem dialogamos demonstra implicação com o desafio escolar, narrados em modos de fazer frente às obrigações postas pela instituição. O imperativo do dever lançado nas dinâmicas familiares de responsabilização não deixa de ser enunciado, ainda que as maneiras de expressá-las mudem significativamente no cotidiano. A presença na escola contém o imperativo, mas modulado pelo domínio de capital cultural e/ou pela longevidade lograda no percurso escolar, pelos sentidos construídos na formação profissional e, também, pelas condições dos estabelecimentos de ensino que se habita.

Além disso, as "formas de presença" que desenhamos, em que pese seus limites e necessidades de aprofundamento futuro, procura indicar modos de atuação variáveis cotidianamente conforme as atividades interpostas, dado que as tomadas de posição podem variar ao longo da carreira e segundo a situação (de uma disciplina ou de um professor para outro, por exemplo). A tarefa que nos colocamos é a de 
não substancializar modos de atuação; reconhecer condicionamentos para ponderar os agenciamentos dos indivíduos em suas experiências.

Há um aspecto, entretanto, que perpassa a habitação da escola, como já enunciado, e que merece problematização. A inclinação à sociabilidade e interatividade (ancorada em mídias sociais), já exploradas na literatura sobre as juventudes, parece-nos um elemento não trivial a considerar na produção da escolarização. Nesse sentido, recorremos a Martín-Barbero (2017) e sua alusão à noção de sensorium de Walter Benjamin, para compreendermos as imbricações em jogo: "La tecnologia hoy remite, mucho más que a la novedad de unos aparatos, a nuevos modos de percepción y de lenguaje, a nuevas sensibilidades y escrituras" (Martín-Barbero, 2017, p. 25).

Aventamos que os jovens-estudantes com quem dialogamos explicitam sensibilidade afeita à interatividade sociável e, nesse sentido, constroem uma relação com o conhecimento desde a afecções interativas, preferencialmente em interlocuções e trocas em rede, trazendo o textual à informalidade da oralidade ou, de outra forma, tomando imagens em movimento como uma oralidade secundária (Martín-Barbero, 2017).

Os "modos de estar-juntos" enfatizados pelos jovens hoje seriam, dentre outras coisas, uma possibilidade de ruptura do anonimato em urbes crescentemente mercantilizadas, desarticuladas e orientadas ao tráfego e à circulação. Nas palavras do autor, trata-se de "novos modos de perceber, de sentir e relacionar-se com o tempo e o espaço, novas maneiras de se reconhecer e se juntar, que os adultos tendem a desvalorizar como "febre passageira"' (Martín-Barbero, 2017, p. 31). Nesse sentido, as redes e a conectividade eletrônicas cumpririam papel relacional e sociabilizante (nem por isso menos paradoxal) contra o isolamento que as cidades podem proporcionar.

Assim, os jovens tenderiam a expressar uma sensibilidade diversa, em contraponto virtual à racionalidade e verticalização dos conteúdos e abordagens escolares, por sua vez congruentes à temporalidade moderna e tributárias das promessas de progresso. E nossas incursões nos indicam a coprodução tensa do estudantil e do juvenil, de forma que os jovens se colocam em disputa cotidiana: desde seus enfrentamentos com o imperativo do dever e suas disposições estéticas, tomam posição pela apropriação da escola.

Ao denominarmos "formas de presença", aludimos também ao "presente" na temporalidade juvenil-estudantil. Retornando a Martuccelli $(2007,2018)$, concebemos a prova social da escolarização entre nossos interlocutores constituída desde o imperativo que perfaz a existência desde uma condição cultural de classe, mas cogitamos que esta é imbricada aos desafios da produção de sentidos ao cotidiano escolar, que perpassam presenças e níveis de ensino (e grupos socioculturais e eles relacionados) na forma de um "estado social" institucionalmente circunscrito. Dessa forma, tal desafio passa pela construção de interatividade e performances sociáveis entre pares e entre alunos e professores, tomando mídias e performances locutórias como suportes.

No que tange aos processos de individuação, as inferências produzidas até o momento sugerem que a escolarização comporta a configuração de "atores metonímicos", uma das figuras do hiperator tributado à América Latina por Martuccelli (2010), dado o trabalho tático dos indivíduos no enfrentamento de tarefas que parecem tomadas pragmaticamente, bem como a diversificação de sentidos cons- 
truída quando as expectativas indicadas pelo sistema institucional não comportam necessariamente garantias. E, nesse ponto, poderíamos aventar a hipótese de uma articulação entre modalidades de individuação. A energia dirigida à fruição do espaço escolar no presente responde metonimicamente à instituição, apropriando, ainda, suportes que potencializem dinâmicas interativas e sociáveis de reconhecimento das singularidades.

\section{REFERÊNCIAS}

ARAÚJO, K.; MARTUCCELLI, D. La inconsistencia posicional: un nuevo concepto sobre la estratificación social. Revista CEPAL, v. 103, p. 165-178, 2011.

BOURDIEU, P. Reprodução cultural e reprodução social. In: BOURDIEU, P. Economia das trocas simbólicas. São Paulo: Perspectiva, 1999, p. 295-336.

BRASIL. Ministério da Educação. Breve evolução do sistema educacional. Brasília: MEC, 2000. Disponível em: https://www.oei.es/Educacion. Acesso em: 14 dez. 2015. CABANES, R. Espaço privado e espaço público: o jogo de suas relações. In: TELLES, V.; CABANES, R. (org.). Nas tramas da cidade: trajetórias urbanas e seus territórios. São Paulo: Humanitas, 2006. p. 389-432.

CORROCHANO, M. C. Trabalho e condição juvenil: permanências, mudanças, desafios. In: NOVAES, R. et al. (org.). Agenda juventude Brasil: leituras sobre uma década de mudanças. Rio de Janeiro: Unirio, 2016. p. 155-174.

CORSEUIL, C. H. et al. Trabalho informal entre jovens brasileiros: considerações sobre a evolução no período 2001-2013. In: SILVA, E. R. (org.). Dimensões da experiência juvenil brasileira e novos desafios às políticas públicas. Brasília: IPEA, 2016. p. 177-197.

DAYRELL, J. A escola faz as juventudes? Reflexões em torno da socialização juvenil. Educação e Sociedade, v. 28, n. 100, p. 1105-1128, 2007. https://doi. org/10.1590/S0101-73302007000300022

DAYRELL, J.; CARRANO, P. Juventude e ensino médio: quem é este aluno que chega à escola? In: DAYRELL, J.; CARRANO, P. Juventude e ensino médio: sujeitos e currículo em diálogo. Belo Horizonte: Editora da UFMG, 2014. p. 101-134.

DAYRELL, J.; JESUS, R. E. Juventude, ensino médio e os processos de exclusão escolar. Educação e Sociedade, v. 37, n. 135, p. 407-423, abr.-jun. 2016. https://doi.org/10.1590/ ES0101-73302016151533

DUBET, F.; MARTUCCELLI, D. La experiencia colegial. In: DUBET, F.; MARTUCCELLI, D. En la escuela: sociología de la experiencia escolar. Buenos Aires: Losada, 1998. p. 187-223.

FIELD, A. Descobrindo a estatística usando o SPSS. Porto Alegre: Artmed, 2009.

FREITAS, M. V. Jovens e escolas: aproximações e distanciamentos. In: PINHEIRO, D. et al. (org.). Agenda juventude Brasil: leitura sobre uma década de mudanças. Rio de Janeiro: Unirio, 2016. p. 129-154. 
INSTITUTO BRASILEIRO DE GEOGRAFIA E ESTATÍSTICA (IBGE). Conceitos. Disponível em: https://www.ibge.gov.br/estatisticas/multidominio/ condicoes-de-vida-desigualdade-e-pobreza/17374-indicadores-sociais-minimos. html?=\&t=notas-tecnicas. Acesso em: dez. 2017.

INSTITUTO BRASILEIRO DE GEOGRAFIA E ESTATÍSTICA (IBGE). Síntese de indicadores sociais: uma análise das condições de vida da população brasileira. Rio de Janeiro: IBGE, 2018.

JOVCHELOVITCH, S. Entrevista narrativa. In: BAUER, M. (org.). Pesquisa qualitativa com texto, imagem e som. Petrópolis: Vozes, 2002. p. 90-113.

JULIÃO, E.; FERREIRA, M. P. As políticas de ampliação de oportunidades educacionais no Brasil e as trajetórias escolares na Educação de Jovens e Adultos no ensino médio do Rio de Janeiro. Arquivos Analíticos de Políticas Educativas, v. 26, n. 156, p. 1-25, 2016. https://doi.org/10.14507/epaa.26.3079

KUBOTA, L. C. Uso de tecnologias da informação e comunicação pelos jovens brasileiros. In: SILVA, E. (org.). Dimensões da experiência juvenil brasileira e novos desafios às políticas públicas. Brasília: IPEA, 2016. p. 199-220.

LAHIRE, B. Sucesso escolar nos meios populares: as razões do improvável. São Paulo: Ática, 1997.

MARGULIS, M.; URRESTI, M. La juventud es más que una palabra. Buenos Aires: Biblos, 1996.

MARTÍN-BARBERO, J. A mudança na percepção da juventude: sociabilidades, tecnicidades e subjetividades entre os jovens. In: BORELLI, S.; FREIRE FILHO, J. (org.). Culturas juvenis no século XXI. São Paulo: Educ, 2008. p. 9-32.

MARTÍN-BARBERO, J. Jóvenes entre el palimpsesto y el hipertexto. Barcelona: Ned, 2017.

MARTUCCELLI, D. Cambio de rumbo: la sociedad a escala del individuo. Santiago: LOM, 2007.

MARTUCCELLI, D. ¿Existen individuos en el Sur? Santiago: LOM, 2010.

MARTUCCELLI, D. La individuación como macrosociología de la sociedad singularista. Persona y Sociedad, v. 24, n. 3, p. 9-29, 2018. https://doi.org/10.11565/ pys.v24i3.196

MOURA, R. O que é periferia urbana. São Paulo: Brasiliense, 1996.

NÚCLEO DE POLÍTICAS EDUCACIONAIS (NuPE/UFPR). Censo Escolar 2017: Laboratório de Dados Educacionais. NuPE/UFPR. Disponível em: https://www. dadoseducacionais.c3sl.ufpr.br/\#/indicadores. Acesso em: ago. 2018.

OBSERVATÓRIO DE PORTO ALEGRE (OBSERVAPOA). Porto Alegre em análise. Séries históricas. Censos Populacionais. IBGE. Disponível em: http:// portoalegreemanalise.procempa.com.br. Acesso em: 17 out. 2017.

PEREIRA, A. B. Outros ritmos em escolas da periferia de São Paulo. Educação \& Realidade, Porto Alegre, v. 41, n. 11, p. 217-237, jan.-mar. 2016. https://doi. org/10.1590/2175-623654713 
SIMMEL, G. A sociabilidade (exemplo de sociologia pura ou formal). In: SIMMEL, G._Questões fundamentais da Sociologia: indivíduo e sociedade. Rio de Janeiro: Zahar, 2006. p. 59-82.

SOUZA,J.A ralé brasileira: como é e como vive. Belo Horizonte: Editora UFMG, 2009. SOUZA, C.; LEÃO, G. Ser jovem e ser aluno: entre a escola e o Facebook. Educação \& Realidade, v. 41, n. 1, p. 279-302,jan.-mar. 2016. https://doi.org/10.14507/epaa.26.3079 SPOSITO, M. Juventude e educação: interações entre a educação escolar e a educação não-formal. Educação e Realidade, v. 33, n. 2, p. 83-98, jul.-dez. 2008.

SPOSITO, M.; SOUZA, R.; SILVA, F. A. A pesquisa sobre jovens no Brasil: traçando novos desafios a partir de dados quantitativos. Educação e Pesquisa, v. 44, e170308, 2018. https://doi.org/10.1590/s1678-4634201712170308

WELLER, W. Grupos de discussão na pesquisa com adolescentes e jovens: aportes teórico-metodológicos e análise de uma experiência com o método. Educação e Pesquisa, São Paulo, v. 32, n. 2, p. 241-260, maio-ago. 2006. https://doi.org/10.1590/ S1517-97022006000200003

ZAGO, N. Processos de escolarização nos meios populares: as contradições da obrigatoriedade escolar. In: NOGUEIRA, M. A. et al. (ors.). Família e escola: trajetórias de escolarização em camadas médias e populares. Petrópolis: Vozes, 2011. p. 17-44.

ZAGO, N. A relação escola-família nos meios populares: apontamentos de um itinerário de pesquisas. In: DAYRELL, J. et al. (org.). Família, escola e juventudes: olhares cruzados Brasil-Portugal. Belo Horizonte: Editora UFMG, 2012. p. 132-150.

ZAN, D.; KRAWCZYK, N. Educação e juventudes sob fortes ameaças. Boletim ANPEd, ano 9, n. 57, jul. 2020.

\section{SOBRE O AUTOR}

Leandro Rogério Pinheiro é doutor em educação pela Universidade do Vale do Rio dos Sinos (UNISINOS). Professor da Universidade Federal do Rio Grande do Sul (UFRGS).

E-mail: leandropinheiro75@gmail.com

Conflitos de interesse: $\mathrm{O}$ autor declara que não possui nenhum interesse comercial ou associativo que represente conflito de interesses em relação ao manuscrito.

Financiamento: Coordenação de Aperfeiçoamento de Pessoal de Nível Superior (CAPES). 